\title{
ANALISIS PRAKTIK INCOME SMOOTHING PADA PERUSAHAAN PERTAMBANGAN DI INDONESIA
}

\author{
Anny Widiasmara* \\ anny.asmara@gmail.com, Prodi Akuntansi, Universitas PGRI Madiun \\ Richo Diana Aviyanti \\ 94richodiana@gmail.com, Prodi Akuntansi, Universitas PGRI Madiun \\ Ayu Krisdiyana \\ ayukrisdiyana3424@gmail.com, Prodi Akuntansi, Universitas PGRI Madiun
}

\begin{abstract}
Abstrak
Fluktuasi laba perusahaan sering dianggap sebagai sinyal buruk yang akan berdampak pada perilaku dysfunctional. Oleh karena itu, penelitian ini menguji pengaruh profitabilitas, ukuran perusahaan, dan leverage terhadap praktik income smoothing. Penelitian dilakukan di perusahaan manufaktur yang terdaftar di Bursa Efek Indonesia. Sampel yang digunakan sebanyak 45 perusahaan. Metode analisis menggunakan analisis regresi berganda. Hasil studi menunjukkan bahwa ukuran perusahaan dan profitabilitas tidak berpengaruh terhadap praktik income smoothing. Leverage berpengaruh terhadap praktik income smoothing. Ukuran perusahaan dan laba tidak menjadi landasan perusahaan untuk melakukan praktik income smoothing karena aktivitas perusahaan berskala besar lebih banyak mendapatkan pengawasan dari berbagai pihak sehingga sangat sulit untuk melakukan tindakan income smoothing. Perusahaan lebih berani melakukan praktik income smoothing ketika memiliki rasio leverage rendah karena saat memiliki rasio leverage rendah perusahaan dianggap dalam keadaan aman dan stabil dari risiko kebangkrutan maupun perilaku menyimpang sehingga perhatian investor dan stakeholder lainnya akan sedikit teralihkan.
\end{abstract}

Kata Kunci : ROA, DER, Total Aset, dan Income Smoothing

\section{ANALYSIS OF INCOME SMOOTHING PRACTICES IN MINING COMPANIES IN INDONESIA}

\begin{abstract}
Fluctuations in company profits are often considered as a bad signal that will have an impact on dysfunctional behavior. Therefore, this study examines the effect of profitability, firm size, and leverage on income smoothing practices. The study was conducted in a manufacturing company listed on the Indonesia Stock Exchange. The sample used as many as 45 companies. The method of analysis used multiple regression analysis. The results of the study show that firm size and profitability have no effect on income smoothing practices. Leverage has an effect on income smoothing practices. Company size and profit are not the basis for companies to carry out income smoothing practices because large-scale company activities get more supervision from various parties so it is very difficult to carry out income smoothing actions. Companies are more daring to practice income smoothing when they have a low leverage ratio because when they have a low leverage ratio, the company is considered safe and stable from the risk of bankruptcy and deviant behavior so that the attention of investors and other stakeholders will be slightly distracted.
\end{abstract}

Keyword: ROA, DER, Total Assets, and Income Smoothing 


\section{PENDAHULUAN}

Laporan keuangan merupakan salah satu indikator keberhasilan manajemen. Salah satu informasi yang digunakan untuk mengukur kinerja manajer adalah laba (Ginantra \& Putra, 2015). Laba rentan digunakan manajemen untuk melakukan perilaku dysfunctional (Handayani \& Fuad, 2015). Salah satu bentuk perilaku dysfunctional adalah perataan laba. Perataan laba dapat berfungsi untuk meminimalisasi fluktuasi laba yang di laporkan agar kinerja manajemen terlihat stabil (Yu, Hagigi, \& Stewart, 2018). Fluktuasi laba dapat merugikan investor karena investor tidak mengetahui kondisi keuangan perusahaan yang sesungguhnya.

Pandemi Covid-19 berdampak pada seluruh sektor industri, salah satunya industri pertambangan. Karakteristik sumberdaya sektor pertambangan yang tidak bisa diperbarui juga dikhawatirkan tidak mampu memenuhi kebutuhan yang terus meningkat. Oleh karena itu, sektor pertambangan dianggap rentan dengan praktik manajemen laba. Manajer dikhawatirkan akan berusaha untuk menarik investor dengan melakukan tindakan manajemen laba yakni income smoothing atau perataan laba. Fakta menunjukkan bahwa sektor pertambangan memiliki fluktuasi laba yang cukup signifikan. Penurunan laba INDY pada kuartal 12019 mencapai 61\% atau US\$ 40,5 juta. Namun, laba tahun 2018 kuartal 1 INDY memperoleh laba sebesar US\$103,8 juta. BRMS juga mengalami hal yang sama, yakni pada tahun 2019 memperoleh laba sebesar US\$ 86.650 namun, pada tahun 2018 BRMS rugi sebesar US\$4,69 juta. Fenomena tersebut dikhawatirkan akan memotivasi manajer untuk melakukan tindakan perataan laba demi membuktikan kestabilan ekonomi perusahaan. Praktik perataan laba akan membuat informasi yang dihasilkan tidak akurat dan merugikan pihak-pihak yang berkepentingan (Ginantra \& Putra, 2015).

Teori agensi menjelaskan bahwa terdapat asimetri informasi hubungan kontrak antara prinsipal dan agen. Agen (manajer) memiliki informasi yang lebih dibandingkan prisipal. Salah satunya informasi yang terkait dengan laba bersih (Jensen \& Meckling, 1976). Laba bersih memiliki kelemahan yakni dapat dibiaskan. Manajer dapat dengan mudah membiaskan laba dengan menunda atau mempercepat laba. Semakin tinggi laba akan berdampak pada tingginya pembayaran kompensasi pada pemerintah maupun masyarakat. Namun, ketika laba semakin rendah reputasi perusahaan juga akan menurun yang berdampak pada kurangnya minat investor untuk berinvestasi. Oleh karena itu, manajer cenderung menginginkan laba yang stabil agar dapat menarik investor sekaligus memberikan keuntungan pada reputasi ekonomi perusahaan (Pradnyandari \& Astika, 2019). Hal tersebut didukung hasil penelitian 
yang membuktikan bahwa profitabilitas berpengaruh positif terhadap income smoothing (Wijaya, Mauren, \& Cahyadi, 2020). Hasil berbeda ditunjukkan pada penelitian Husaini \& Sayunita (2016) yang menyatakan bahwa profitabilitas berpengaruh negatif terhadap income smoothing.

Besar kecilnya perusahaan juga berpengaruh terhadap income smoothing. Perusahaan berskala besar cenderung bertindak hati-hati dalam mengelola labanya serta cenderung mengelola laba seefisien mungkin. Hal ini dikarenakan banyak badan pengawas dan aturan untuk mengawasi tindakan dysfunctional. Selain itu, terdapat kemudahan akses informasi di perusahaan Perusahaan berskala besar dibandingkan perusahaan kecil (Handoyo \& Fathurrizki, 2018). Perusahaan berskala besar biasanya memiliki transaksi yang kompleks sehingga melakukan praktik income smoothing merupakan tindakan yang sulit (Handoyo \& Fathurrizki, 2018). Hasil sebaliknya menunjukkan bahwa perusahaan berskala besar memiliki stakeholder yang kompleks sehingga cenderung melakukan income smoothing untuk untuk menjaga reputasi perusahaan (Josep, Dzulkirom, \& Azizah, 2016).

Teori agensi menyatakan bahwa manusia adalah makhluk yang rasional dan cenderung ingin menguntungkan dirinya (Jensen \& Meckling, 1976). Ketika rasio leverage perusahaan tinggi maka akan diiringi dengan meningkatnya risiko kebangkrutan. Kebangkrutan perusahaan tentu akan merugikan pihak prinsipal maupun agen. Oleh karena itu, manajer akan berusaha menstabilkan kondisi tersebut dengan perataan laba. Hal tersebut didukung penelitian Efrinal \& Chandra (2020) yang membuktikan bahwa leverage berpengaruh positif terhadap praktik income smoothing, penelitian Sanjaya \& Suryadi (2018) berpengaruh negatif terhadap income smoothing, sedangkan hasil penelitian Aditya \& Sufiyati (2021) menunjukkan leverage tidak berpengaruh terhadap income smoothing.

Hasil studi sebelumnya yang tidak konsisten memotivasi peneliti untuk menguji kembali pengaruh profitabilitas, leverage, dan ukuran perusahaan terhadap praktik income smoothing. Studi ini menggunakan data terbaru dan kondisi yang berbeda.

\section{TINJAUAN PUSTAKA}

\section{Teori Agensi}

Teori agensi memiliki asumsi bahwa individu semata-mata termotivasi oleh kepentingan dirinya sendiri sehingga menimbulkan konflik kepentingan antara principal dan agent (Jensen \& Meckling, 1976). Pertentangan kepentingan yang dapat terjadi salah satunya karena prinsipal ingin mencapai profitabilitas maksimal dan meningkat, sedangkan agen juga 
ingin memaksimalkan keinginannya sendiri melalui kontrak kompensasi. Konflik keangenan seringkali disebabkan oleh konflik kepentingan tersebut. Keleluasan informasi yang dimiliki oleh agen dapat memberikan kesempatan bagi manajemen perusahaan untuk melakukan tindakan menyimpang yang cenderung memberikan keuntungan bagi golongan tertentu.

Kontrak hubungan antara principal dan agen memungkinkan mereka untuk saling mendahulukan kepentingannya masing-masing. Agen diasumsikan akan bekerja keras memperoleh keuntungan yang sebesar-besarnya tanpa memperhatikan apakah tindakan yang dilakukan sesuai dengan standar yang berlaku atau tidak. Agen juga akan melakukan berbagai cara untuk memperoleh informasi yang luas sehingga kepentingan golongan dapat terfasilitasi (Handoyo \& Fathurrizki, 2018). Sedangkan, prinsipal diasumsikan hanya tertarik terhadap pengembalian investasi yang tinggi. Konflik kepentingan antara prinsipal dan agen memungkinkan salah satu pihak diuntungkan sedangkan pihak yang satunya akan dirugikan.

\section{Income Smoothing}

Income smoothing atau perataan laba merupakan salah satu cara yang digunakan manajer untuk melakukan manipulasi data transaksi (Mahastanti \& Pratiwi, 2014). Manipulasi bisa dilakukan dari segi waktu laba atau laporan laba sehingga laba yang dilaporkan terlihat stabil. Income smoothing termasuk dalam salah satu bentuk manajemen laba dengan cara menambah atau mengurangi laba yang dilaporkan untuk mengurangi fluktuasi laba perusahaan antar periode (Pardistya, 2020). Aktivitas memperkecil laba dilakukan saat laba perusahaan sedang meningkat serta memperbesar laba dilakukan saat laba perusahaan sedang menurun (Paramita \& Isarofah, 2016). Laba yang stabil diharapkan akan menciptakan persepsi investor tentang kondisi perusahaan yang baik. Aktivitas income smoothing secara sengaja dilakukan untuk menarik keinginan pasar untuk berinvestasi. Investor jarang memperhatikan prosedur yang digunakan manajer untuk menghasilkan laba dan biasanya hanya melihat kondisi perusahaan terpantau stabil atau tidak (Pardistya, 2020).

\section{Pengaruh Profitabilitas Terhadap Income Smoothing}

Profitabilitas adalah kemampuan perusahaan untuk menghasilkan laba dari jumlah laba bersih dan total asetnya atau sering disebut ROA (Paramita \& Isarofah, 2016). Rendahnya rasio profitabilitas menjadi salah satu indikator yang dipakai investor maupun kreditor dalam menilai kondisi perusahaan (Aditya \& Sufiyati, 2021). Oleh karena itu, manajer akan berusaha meningkatkan rasio profitabilitas agar nilai perusahaan maupun kinerja manajer 
terlihat baik. Hal tersebut berdampak pada terciptanya reputasi perusahaan dan meningkatkan kepercayaan investor. Namun, ketika laba terlalu tinggi juga akan berdampak pada biaya kompensasi laba seperti pembayaran pajak, biaya CSR, dan lainnya sehingga manajer cenderung menginginkan laba yang stabil agar dapat menarik investor sekaligus memberikan keuntungan pada reputasi ekonomi perusahaan (Pradnyandari \& Astika, 2019). Hal tersebut didukung hasil penelitian yang membuktikan bahwa profitabilitas berpengaruh positif terhadap income smoothing (Wijaya et al., 2020).

\section{H1: ROA berpengaruh terhadap praktik income smoothing}

\section{Pengaruh Leverage Terhadap Income Smoothing}

Tingkat leverage merupakan hal yang berkaitan dengan liabilitas perusahaan. Perusahaan yang memiliki tingkat liabilitas yang tinggi cenderung mendapat persepsi negatif tentang kemampuan keberlanjutan perusahaan. Oleh karena itu, perusahaan akan melakukan income smoothing menaikan laba untuk untuk menghindari kebangkrutan dan menjaga reputasi dari kreditor maupun investor. Kondisi perusahaan yang stabil tentu lebih dipercaya oleh kreditor maupun investor dibandingkan dengan perusahaan yang memiliki kondisi fluktuatif. Hal tersebut didasarkan pada keyakinan bahwa perusahaan dengan laba yang stabil akan lebih meyakinkan untuk membayar liabilitasnya dan terhindar dari risiko gagal bayar maupun kebangkrutan.

Hasil studi juga membuktikan bahwa leverage berpengaruh positif terhadap income smoothing (Deli \& Irfan, 2019; Efrinal \& Chandra, 2020).

\section{H2: Leverage berpengaruh terhadap praktik income smoothing}

\section{Pengaruh Ukuran Perusahaan Terhadap Income Smoothing}

Perusahaan berskala besar biasanya memiliki sumberdaya manusia yang memiliki kemampuan melakukan tindakan akuntansi kreatif (Alexandri \& Anjani, 2014; Handoyo \& Fathurrizki, 2018). Oleh karena itu, perusahaan berskala besar dianggap cenderung lebih mudah dalam "memainkan" metode akuntansi dalam manajemen laba. Stakeholder yang dimiliki perusahaan berskala besar cenderung lebih banyak dan kompleks, sehingga perusahaan diperkirakan akan menghindari fluktuasi laba secara drastis untuk menjaga ke stabilan perusahaan. Akses informasi keuangan perusahaan berskala besar biasanya juga cenderung lebih mudah dilakukan dibandingkan perusahaan kecil sehingga sebisa mungkin manajer akan mempertahankan reputasi perusahaan dan kinerjanya. Hasil studi juga 
menunjukkan bahwa semakin besar skala perusahaan maka semakin tinggi pula praktik income smoothing (Pradnyandari \& Astika, 2019).

\section{H3 : Ukuran perusahaan berpengaruh terhadap praktik income smoothing}

\section{METODE}

\section{Populasi dan Sampel}

Populasi penelitian ini adalah perusahaan Pertambangan yang terdaftar di Bursa Efek Indonesia (BEI) pada tahun 2018-2020 yang berjumlah sebanyak 169 perusahaan yang terbagi dalam 3 sektor yakni sektor industri dasar dan kimia, sektor aneka industri, dan sektor industri barang konsumsi. Sampel yang digunakan sebesar 48 perusahaan pertambangan terdaftar di BEI yang menerbitkan laporan tahunan (Annual Report) pada periode 2018-2020. Metode penentuan sampel menggunakan purposive sampling dengan mempertimbangkan tersedianya informasi laporan keuangan, outlier, dan tidak delisting pada periode penelitian.

Tabel 1: Kriteria Pengambilan Sampel

\begin{tabular}{lc}
\hline \multicolumn{1}{c}{ Kriteria } & Jumlah \\
\hline Perusahaan Pertambangan yang tercatat di BEI & 48 \\
Perusahaan Pertambangan yang mengalami delisting selama tahun 2018- & - \\
2020 & \\
Perusahaan Pertambangan yang memiliki informasi dalam laporan keuangan & $(3)$ \\
tidak lengkap selama 2018-2020 & \\
Sampel Perusahaan & 45 \\
Periode amatan 3 tahun maka total amatan 3x45 & 135 \\
Outliers & $(67)$ \\
Jumlah amatan setelah dikurangi outliers & 77 \\
\hline
\end{tabular}

\section{Teknik Pengumpulan data}

Data yang digunakan adalah data sekunder yang berasal dari laporan keuangan tahunan perusahaan 2018-2020 yang terpublish di web masing-masing perusahaan atau BEI.

Tabel 2: Definisi Operasional Variabel dan Pengukurannya

\begin{tabular}{clll}
\hline Variabel & \multicolumn{1}{c}{ Definisi } & \multicolumn{1}{c}{ Pengukuran } & \multicolumn{1}{c}{ Sumber } \\
\hline Profitabilitas & Kemampuan perusahaan & ROA = Net & Husaini \& Sayunita \\
& dalam menghasilkan laba & Income/Total Asset & (2016); Paramita \&
\end{tabular}




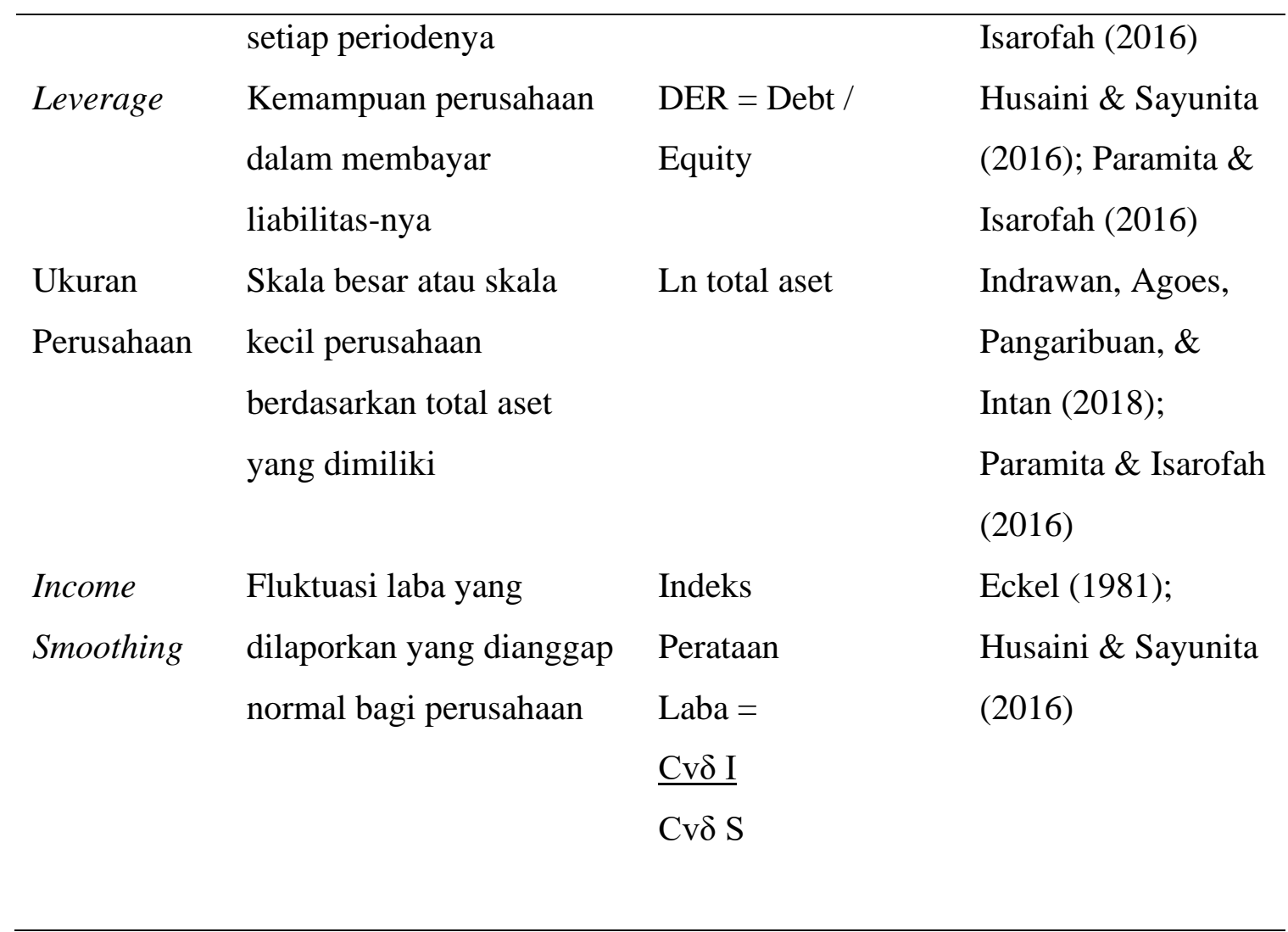

\section{Teknik Analisis Data}

Analisis data menggunakan adalah regresi linear berganda. Tahapan uji yang dilakukan adalah uji parsial, uji normalitas, uji Multikolinearitas, uji Heteroskedastisitas, uji Autokorelasi, dan uji $\mathrm{R}^{2}$

$$
\mathrm{Y}=\mathrm{a}+\mathrm{b} 1 \mathrm{X} 1+\mathrm{b} 2 \mathrm{X} 2+\mathrm{b} 3 \mathrm{X} 3+\varepsilon
$$

Y: Income Smoothing

X1: ROA

X2: DER

X3: Ln Total aset

\section{HASIL DAN PEMBAHASAN}

\section{Statistika Deskriptif}

Tabel 3: Hasil Statistika Deskriptif

\begin{tabular}{lcccc}
\hline \multicolumn{1}{c}{ Variabel } & Minimum & Maximum & Mean & Std. Deviation \\
\hline ROA & 77 & $-0,08$ & 0,15 & 0,05410 \\
DER & 77 & 0,00 & 3,43 & 0,77373 \\
UK_PERSH & 77 & 26,83 & 32,38 & 1,60695
\end{tabular}




IN_SMOOTH $77 \quad-1,24 \quad 0,94 \quad 0,38216$

Berdasarkan tabel 3 diketahui bahwa seluruh variabel memperoleh nilai rata-rata yang lebih besar dibandingkan nilai standar deviasinya maka dapat disimpulkan bahwa data yang digunakan heterogen atau menyebar secara merata.

\section{Uji Hipotesis dan Analisis}

Tabel 4: Hasil Uji Model Regresi

\begin{tabular}{lcccl}
\hline \multicolumn{1}{c}{ Variabel } & Koefisien & Nilai t & Sig. & Keputusan \\
\hline ROA & $-0,0765$ & $-0,0942$ & 0,349 & H1 ditolak \\
DER & $-0,173$ & $-2,862$ & $0,005^{*}$ & H2 diterima \\
UK_PERSH & 0,030 & 1,045 & 0,299 & H3 ditolak \\
Adj R2 & 0,0064 & & & \\
\hline
\end{tabular}

Model regresi dalam penelitian ini telah memenuhi uji asumsi klasik yakni uji normalitas, heterokedastisitas serta multikolinearitas. Hasil regresi dari penelitian ini disajikan pada Tabel 4. Hasil nilai $\mathrm{R}^{2}$ menunjukkan sebesar 0,064 artinya variabel dalam model mampu memengaruhi income smoothing sebesar 6,4\% serta sisanya dipengaruhi oleh variabel lain yang tidak termasuk dalam model penelitian.

Hasil dari pengujian menunjukkan bahwa variabel profitabilitas (ROA) berpengaruh negatif terhadap praktik income smoothing. Koefisien bertanda negatif $(-0,0765)$ dengan signifikasi lebih dari 0,05 (0,349>0,05) maka dapat disimpulkan bahwa H1 tidak didukung. Dapat dinyatakan bahwa ROA tidak berpengaruh terhadap indikasi praktik income smoothing. Perusahaan dengan laba tinggi tidak melakukan praktik income smoothing dengan menurunkan tingkat laba. Perusahaan saat ini cenderung bertindak hati-hati dalam mengelola labanya serta cenderung mengelola laba seefisien mungkin. Hal ini dikarenakan banyak badan pengawas dan aturan untuk mengawasi tindakan dysfunctional. Hasil sesuai dengan penelitian Sanjaya \& Suryadi (2018) yang membuktikan bahwa ROA tidak berpengaruh terhadap praktik income smoothing.

Variabel ukuran perusahaan (UK_PERSH) memiliki nilai koefisien positif $(0,030)$ dengan nilai signifikansi lebih dari 0,05 (0,299>0,05). Artinya, ukuran perusahaan tidak berpengaruh terhadap praktik income smoothing (H2 tidak didukung). Perusahaan berskala besar tidak melakukan praktik income smoothing karena saat ini telah banyak pengawasan utamanya untuk perusahaan berskala besar serta transaksi yang dilakukan sangat banyak dan 
kompleks sehingga sangat sulit untuk melakukan tindakan income smoothing. Hasil penelitian sesuai dengan penelitian Handoyo \& Fathurrizki (2018) dan Sanjaya \& Suryadi (2018).

Hasil uji variabel leverage (DER) menunjukkan koefisien bernilai negatif $(-0,173)$ dan nilai signifikansi $<0,05(0,005)$ artinya DER berpengaruh negatif signifikan terhadap praktik income smoothing. Semakin tinggi rasio hutang maka perusahaan cenderung rendah melakukan income smoothing (H3 tidak didukung). Saat ini telah banyak aturan maupun pengawasan dari regulator terkait perilaku dysfunctional. Oleh karena itu, manajemen tetap enggan melakukan praktik manajemen laba meskipun liabilitas perusahaan sedang tinggi. Saat ini, akses untuk mencari informasi pada suatu perusahaan juga sudah mudah sehingga reputasi manajemen dan perusahaan dipertaruhkan ketika manajemen melakukan tindakan menyimpang. Reputasi diyakini menjadi hal yang lebih penting dibandingkan dengan fluktuasi keuangan perusahaan. Hasil uji bernilai negatif juga memungkinkan manajemen melakukan income smoothing ketika kondisi liabilitas perusahaan sedang rendah. Hal ini dikarenakan perusahaan yang memiliki leverage tinggi akan lebih berisiko dibandingkan dengan perusahaan yang memiliki leverage rendah (Paramita \& Isarofah, 2016). Oleh karena itu, perusahaan akan melakukan income smoothing ketika kondisi liabilitas perusahaan sedang rendah. Hal tersebut sesuai dengan studi yang dilakukan yang menyatakan bahwa leverage berpengaruh negatif terhadap praktik income smoothing (Sanjaya \& Suryadi, 2018).

\section{SIMPULAN}

Perilaku dysfunctional saat ini sulit dilakukan karena banyaknya pengawasan dari berbagai sisi. Perusahaan pertambangan di BEI yang menjadi sampel penelitian cenderung rendah dalam melakukan praktik income smoothing. Ukuran perusahaan dan profitabilitas tidak berpengaruh terhadap praktik income smoothing. Dapat dinyatakan bahwa ukuran perusahaan dan laba tidak menjadi acuan untuk melakukan praktik income smoothing. Leverage berpengaruh negatif terhadap praktik income smoothing. Artinya, perusahaan lebih berani melakukan praktik income smoothing ketika memiliki rasio leverage rendah. Hasil penelitian dapat digunakan untuk menambah bukti empiris tentang income smoothing, teori agensi serta menambah tingkat sebaran generalisasi. Investor, kreditor, dan pihak lain yang berkepentingan disarankan waspada ketika nilai leverage perusahaan rendah.

\section{DAFTAR PUSTAKA}

Aditya, I., \& Sufiyati. (2021). Faktor-faktor yang Mempengaruhi Income Smoothing pada 
Perusahaan di BEI. Jurnal Multiparadigma Akuntansi, 3(2), 712-720.

Alexandri, M. B., \& Anjani, W. K. (2014). Income Smoothing: Impact Factors, Evidence in Indonesia. International Journal of Small Business and Entrepreneurship Research, 3(1), $21-27$.

Deli, L., \& Irfan. (2019). Faktor-Faktor Yang Mempengaruhi Income Smoothing Pada Perusahaan Tekstil Dan Garmen Yang Terdaftar Di Bursa Efek Indonesia. Accumulated Journal, 1(2), 105-116.

Eckel, N. (1981). The Income Smooting Hypothesis Revisited. Abacus, 6, $28-40$.

Efrinal, \& Chandra, A. H. (2020). Pengaruh Profitabilitas, Ukuran Perusahaan, Financial Leverage dan Likuiditas terhadap Perataan Laba. Akuntansi Dan Keuangan, 2(2), 135148.

Ginantra, I. K. G., \& Putra, I. N. W. A. (2015). Pengaruh Profitabilitas, Leverage, Ukuran Perusahaan, Kepemilikan Publik, Dividend Payout Ratio Dan Net Profit Margin Pada Perataan Laba. E-Jurnal Akuntansi Universitas Udayana, 2(10), 602-617.

Handayani, F., \& Fuad. (2015). Faktor yang Berpengaruh Terhadap Perataan Laba Perusahaan Otomotif yang Terdaftar di Bursa Efek Indonesia (BEI) 2009-2012. Diponegoro Journal Of Accounting, 4(2), 1-12.

Handoyo, S., \& Fathurrizki, S. (2018). Management Dysfunctional Behaviour toward Financial Statements: Income Smoothing Practice in Indonesia's Mining Industry Sector. Jurnal Keuangan Dan Perbankan, 22(3), 429-442. https://doi.org/10.26905/jkdp.v22i3.2047

Husaini, \& Sayunita. (2016). Determinant of Income Smoothing At Manufacturing Firms Listed On Indonesia Stock Exchange. International Journal of Business and Management Invention, 5(9), 01-04. Retrieved from www.ijbmi.org

Indrawan, V., Agoes, S., Pangaribuan, H., \& Intan, O. M. J. P. T. P. (2018). The Impact of Audit Committee, Firm Size, Profitability, and Leverage on Income Smoothing. IndianPacific Journal of Accounting and Finance (IPJAF), 2(1), 61-74.

Jensen, M. C., \& Meckling, W. H. (1976). Theory of the firm: Managerial behavior, agency costs and ownership structure. Journal of Financial Economics, 3(4), 305-360.

Josep, W. H., Dzulkirom, M., \& Azizah, D. F. (2016). Pengaruh Ukuran Perusahaan, Return on Asser dan Net Profit Margin Terhadap Perataan Laba (Income Smoothing): Studi pada Perusahaan Manufaktur yang Terdaftar di BEI 2012-2014. Jurnal Administrasi Bisnis (JAB), 33(2), 94-103.

Mahastanti, L. A., \& Pratiwi, S. O. (2014). Income Smoothing Phenomen on in Indonesia: Garbling Vs Signalling. In The 2nd IBEA - International Conference on Business, Economics and Accounting Hong Kong, 26 - 28 March 2014 INCOME (pp. 26-28).

Paramita, R. W. D., \& Isarofah. (2016). Income Smoothing: Apakah Ukuran Perusahaan 
Memoderasi? Journal of Research and Applications: Accounting and Management, 2(1), 55. https://doi.org/10.18382/jraam.v2i1.93

Pardistya, I. Y. (2020). Income Smoothing Analysis in the Company (Case Study At Pt. Kalbe Farma. Tbk Year 2017-2019). Jurnal Terapan Manajemen Dan Bisnis, 6(1), 23. https://doi.org/10.26737/jtmb.v6i1.2276

Pradnyandari, A. A. I. R., \& Astika, I. B. P. (2019). Pengaruh Ukuran Perusahaan, Nilai Saham, Financial Leverage, Profitabilitas Pada Tindakan Perataan Laba di Sektor $\begin{array}{llll}\text { Manufaktur. E-Jurnal } & \text { Akuntansi, }\end{array}$ https://doi.org/10.24843/eja.2019.v27.i01.p06

Sanjaya, W., \& Suryadi, L. (2018). Faktor-Faktor Yang Mempengaruhi Income Smoothing Pada Perusahaan Manufaktur Periode 2014-2016. Jurnal Ekonomi, XXIII(03), 347-358.

Wijaya, H., Mauren, \& Cahyadi, H. (2020). Factors Influencing Income Smoothing Practices With Firm Size Moderation. Jurnal Akuntansi, 24(2), 250-265. https://doi.org/10.24912/ja.v24i2.695

Yu, K., Hagigi, M., \& Stewart, S. D. (2018). Income smoothing may result in increased perceived riskiness: Evidence from bid-ask spreads around loss announcements. Journal of Corporate Finance, 48, 442-459. https://doi.org/10.1016/j.jcorpfin.2017.11.007 